\title{
Severe eosinophilia and toxoplasmosis - an uncommon association.
}

Aaqib Banday ${ }^{1}$, Dharmagat Bhattarai ${ }^{1}$, Naveen Bhagat ${ }^{1}$, Sreejesh Sreedharanunni ${ }^{1}$, Sumeeta Khurana ${ }^{1}$, and Deepti Suri ${ }^{1}$

${ }^{1}$ Post Graduate Institute of Medical Education and Research

May 18, 2020

Title:

Severe eosinophilia and toxoplasmosis - an uncommon association.

Authors:

Aaqib Zaffar Banday*, Dharmagat Bhattarai*, Naveen Bhagat*, Sreejesh Sreedharanunni\#, Sumeeta Khurana\$, Deepti Suri*.

\section{Affiliations:}

*Allergy Immunology Unit, Department of Pediatrics, Advanced Pediatrics Centre, Post Graduate Institute of Medical Education and Research (PGIMER), Chandigarh (India).

\#Department of Hematology, Research block-A, Post Graduate Institute of Medical Education and Research (PGIMER), Chandigarh (India).

\$ Department of Parasitology, Research block-A, Post Graduate Institute of Medical Education and Research (PGIMER), Chandigarh (India).

Corresponding author details:

Dr. Deepti Suri, M.D.

Additional Professor of Pediatrics (Clinical Immunology and Rheumatology Division), Allergy Immunology Unit, Department of Pediatrics, Advanced Pediatrics Centre, PGIMER,

Chandigarh (INDIA) - 160012

Mobile- +91-7087-008316

E mail: surideepti@gmail.com

Word counts: 773

Tables: 0

Figures: 1

Supplementary figures: 0

Supplementary tables: 1

Key words: Allergy; Azithromycin; Cotrimoxazole; Hypereosinophilia; Pediatric; Steroid; Toxoplasma.

Running title: Pediatric hypereosinophilia and toxoplasma.

Conflict of interest: None 
Funding source: None

Ethical approval and informed consent: As this manuscript pertains only to a case report specific ethics approval is not mandated. An informed consent was taken from parents of the child before inclusion into the manuscript.

Competing interest for all authors: No financial or nonfinancial benefits have been received or will be received from any party related directly or indirectly to the subject of this article.

Acknowledgement: The authors thank Prof. Surjit Singh for his valuable opinion regarding patient management.

\section{Author contribution statement :}

AZB: Inception of idea, writing of initial draft of manuscript, editing and revision of manuscript at all stages of its production, patient evaluation, management and follow-up, review of literature.

DB/NB: Evaluation and management of the patient, editing of manuscript.

SS: P erformed hematology workup of the child and genetic analysis, editing of the manuscript at all stages.

SK: Performed parasitology workup of the child, editing of the manuscript at all stages.

DS: Critical revision of the manuscript at all stages of production and final approval.

\section{Hosted file}

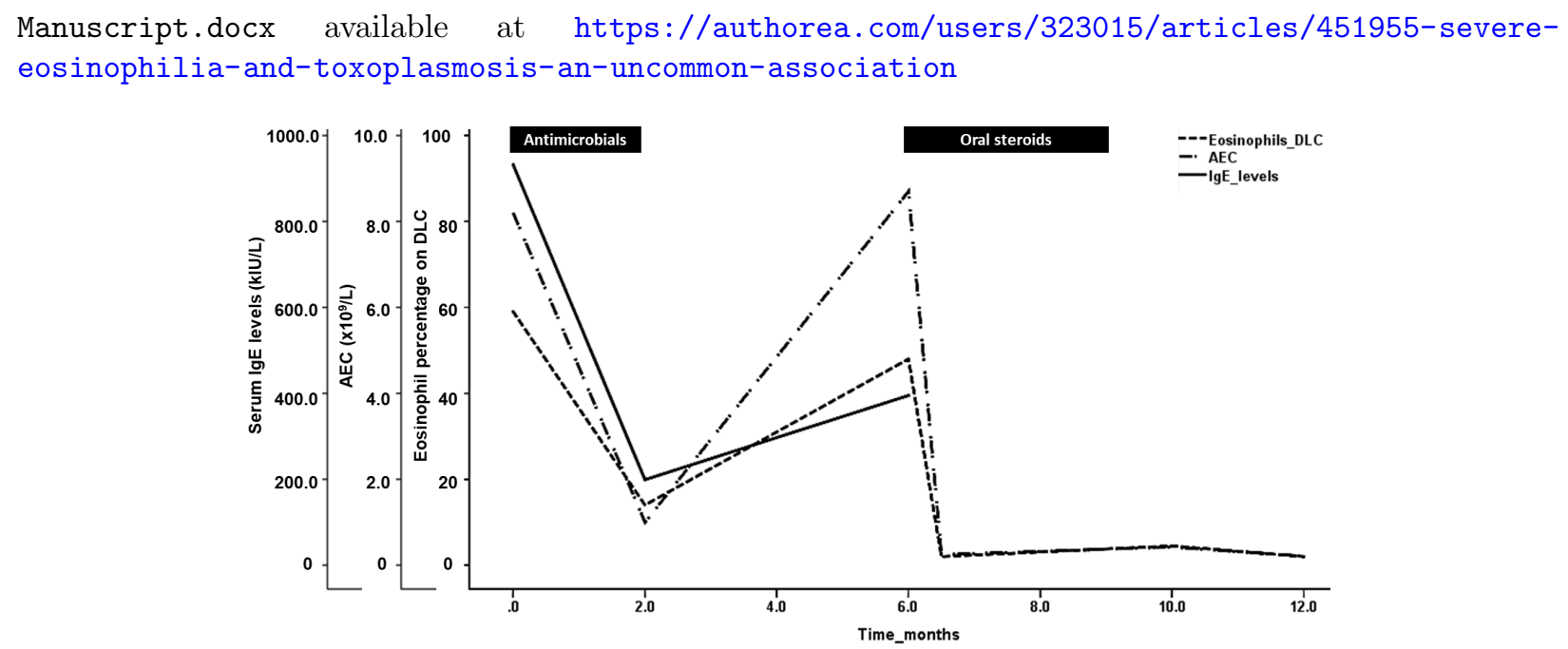

